\section{Asymmetries for Ameslan handshapes and other forms in signers and nonsigners}

\author{
SUSAN VIROSTEK and JAMES E. CUTTING \\ Wesleyan University, Middletown, Connecticut 06457
}

Much recent research has addressed the question of cerebral asymmetry in the perception of American Sign Language (Ameslan). The question has, of course, been prompted by the traditional characterization of the left hemisphere as specialized for language and the right for visuospatial or nonlinguistic functions. Since Ameslan carries a complexity and regularity analogous to that of spoken languages into the visual modality, the issue has been posed as one pertinent to the study of cerebral specialization in general. However, since several studies have demonstrated left-hemisphere advantages for nonlinguistic forms (Bever \& Chiarello, 1974; Patterson \& Bradshaw, 1975) and since others have shown right-hemisphere linguistic capacities (for a review, see Searleman, 1977), the question of asymmetries in the perception of sign language is by no means clear-cut. Indeed, variability of results in this domain have been extensively documented by Poizner and Battison (in press) and Poizner, Battison, and Lane (1979), and lend force to the notion that the study of hemisphere specialization in sign is complex.

Our point in this note is to compare two previous studies (Phippard, 1977; Poizner \& Lane, 1979) with our own, presented here for the first time. All were conducted independently at about the same time, and are very similar in design. Yet the results are somewhat different. To facilitate discussion, we present our study first.

\section{METHOD}

\section{Subjects}

Three groups of viewers participated in the experiment. The first consisted of eight congenitally deaf signers. They were high school students at the American School for the Deaf in West Hartford, Connecticut, and had varying, severely limited speech capacities.

This work was supported by small research grants to both authors from Wesleyan University, and by NIH Grant MH33087 to the second author. We thank Leo Burke, our sign informant, and Nancy Frishberg for their aid in early stages of the project; John Seamon and Robert White for technical assistance; Michael Rosano, Jack LaBlond, and William Breck for facilitating entry into the schools; and the American School for the Deaf, Northwestern Connecticut Community College, and Coginchaug Regional High School for their forebearance. Susan Virostek is presently at Columbia University. Requests for reprints may be sent to J. Cutting, Department of Psychology, Wesleyan University, Middletown, Connecticut 06457.
All had deaf parents and had learned Ameslan as a first language. It is unfortunate that this group could not be larger, but deaf people with two deaf parents are difficult to locate. They comprise only about 1 out of every 10,000 people in this country, and it is only with this group that one can be sure that sign is the native language. The second group consisted of eight hearing interpreters of sign: Seven were students in an advanced interpreting class in Career Programs for the Deaf at Northwestern Connecticut Community College in Winsted, Connecticut, and the eighth was dormitory supervisor at the American School. A third control group of nonsigners was made up of 16 teachers at the Coginchaug Regional High School in Durham, Connecticut. Mean ages of the groups were 17,22 , and 32 years, respectively. Although the difference in ages is marked, there is nothing in the literature to suggest that hemisphere differences alter between puberty and early adulthood. Each participant used the right hand for writing, and, in the cases of those in the first two groups, for designating signs as well.

\section{Stimuli}

Four sets of stimuli determined the experimental conditions for a tachistoscopic matching task. They are shown in the left panel of Figure 1 and will be considered in order of clockwise arrangement. Note first, that all are static shapes, yet sign language is fundamentally dynamic. We have chosen to use static sign shapes because (1) dynamic visual presentation to separate hemifield is methodologically difficult (see Poizner, Battison, \& Lane, 1979), and (2) in the current study we are less interested in mapping the structure of sign than in mapping the neurological correlates of the perception of symbolic and nonsymbolic handshapes.

Two sets consisted of legitimate configurations in Ameslan, and are designated as "alphabetical" and "numerical." Seven of the eight handshapes have been examined for distinctive features (Lane, Boyes-Braem, \& Bellugi, 1976). The "alphabetical" shapes are compact, having no fingers extended. $\mathrm{C}$ and $\mathrm{O}$ are also concave, with bent fingers that are neither extended nor closed. $\mathrm{E}$ and $\mathrm{O}$ have the feature touch, with fingers contacting the thumb. All four "numerical" handshapes are noncompact. Those with three and four fingers extended are broad, and, together with the two-finger shape, are also spread, having two or more fingers extending at right angles to the palm. The onefinger shape has none of the above features, but is one of a class called index.

The items in the first set are meaningful only to signers: letters of the manual alphabet frequently used as handshapes for lexical items. The items in the second set are also noted in this manner in sign, but are included here as a control for codability. These are meaningful handshapes for signers and nonsigners alike, roughly designating cardinal numbers 1 through 4 . The three-fingered handshape of the second set also represents $\mathrm{W}$ and 6 in the manual alphabet; hence it was not anticipated that the signers would necessarily consider the second set as a numerical group. Most, however, mentioned in a postexperiment interview that they did.

The third set of stimuli served as a second control, consisting of handshapes that are illegitimate in Ameslan. These have no symbolic or linguistic significance for either signers or nonsigners. The fourth set served as a third control, consisting of straightline shapes that varied in angle of indentation at the top. These were designed to be similar to numerical and illegitimate handshapes, but to be not identifiable as hands.

Stimuli were presented to viewers by video tape and television monitor. They had been prerecorded from a two-channel tachistoscope. Preparation of the stimulus tapes involved several steps. First, photographs were taken of the right hand of an 

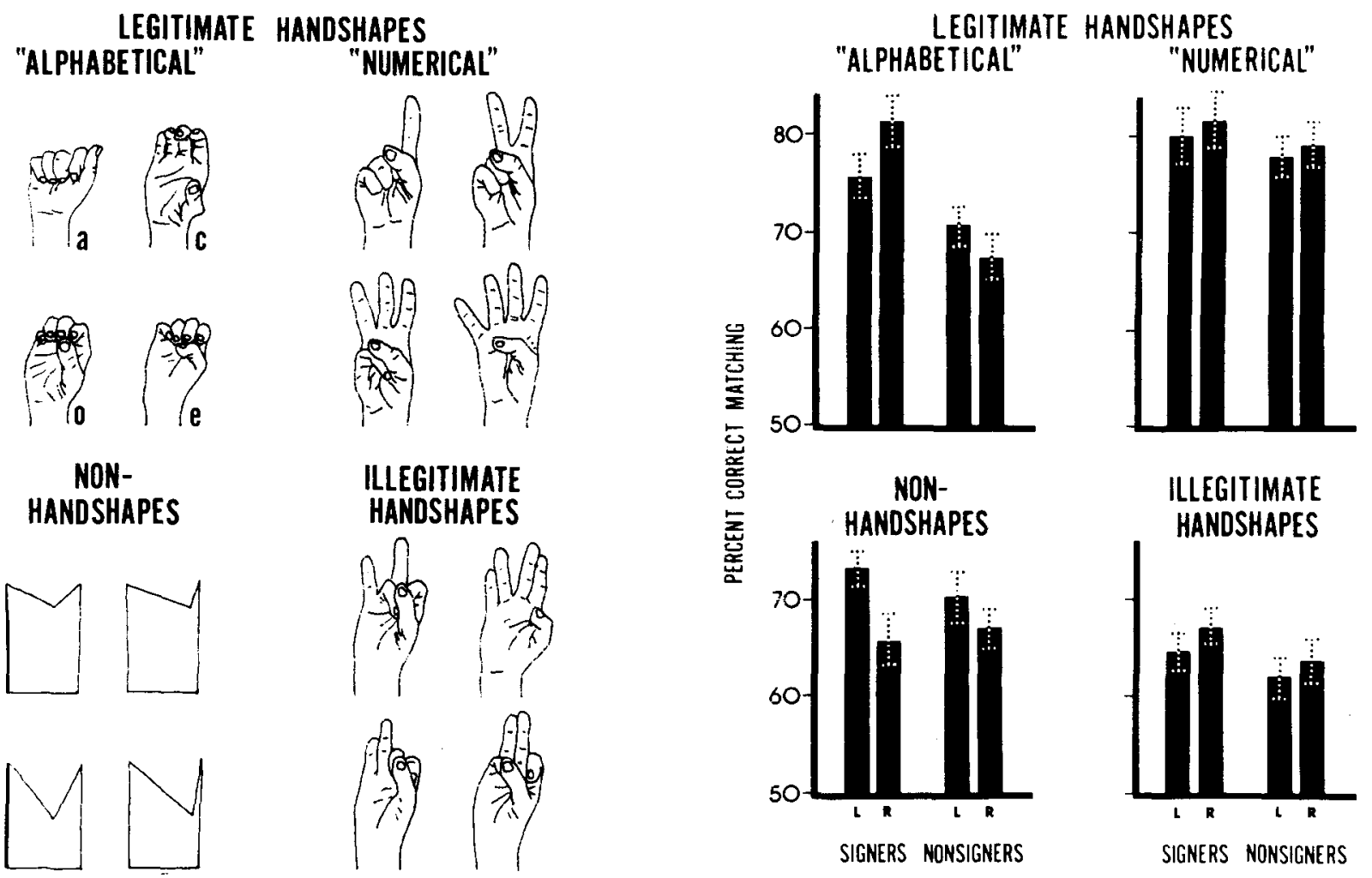

Figure 1. In the left panel are right-hand versions of the stimuli that determined each of the four conditions. In the right panel are results for each condition. $L=$ left visual field, and $R=$ right visual field. The small markings atop each bar indicate \pm one stan dard error of the mean. Care should be taken in the interpretation of results in terms of the category labels "alphabetical" and "numerical." Distinctive features of these signs may be more important than category class.

adult native signer making the chosen handshapes. Next, line drawings were traced from them, rephotographed, and converted into white-on-black slides. Finally, test orders were recorded from the tachistoscope via a rear-projection screen, using a Sony-Matic solid state videorecorder (Model AV3650) and a GBC Viewfinder camera (Model VF-302).

A single trial presented two shapes. The first appeared $3 \mathrm{deg}$ 40 min to one side of a central fixation point, followed by the second at fixation. Both were presented for $100 \mathrm{msec}$ with a $10-\mathrm{msec}$ interval between. The first shape appeared equally often in left and right visual fields, and was paired equally often with itself and with a different shape from the same set.

All pairs occurred in the orientation shown in Figure 1 and in mirror image as well. For example, they appeared as left and right hands in the case of all handshapes. This is important since the radial portion of the hand (from midline to thumb) carries more information thar the ulnar portion. If right hands were used exclusively as stimuli, the LVF might be differentially favored. No stimulus pair consisted of a shape and its mirror image. Each possible "different" combination did not appear equally often; rather, those previously determined to be more confusable were chosen to be more frequent. Nevertheless, chosen pairs occurred equally often in both fields and in both orientations.

\section{Procedure}

Each of four conditions consisted of 64 trials, with a $4 \mathrm{sec}$ intertrial interval. Within groups, viewers were randomly assigned to one of four counterbalanced test orders, each test employing one of the four types of stimuli. Viewers were allowed to examine fabric templates of the handshapes prior to each condition. They were then instructed in their native language to write $S$ if the shapes in each trial appeared the same and D if they appeared different. They were told to guess whenever they were uncertain of a response. Missed trials, occurring because of a blink or excessive noise on the video monitors, were discarded. Mean numbers of missed trials (out of 64 ) were .78 for the deaf, .50 for the interpreters, and .58 for the controls.

Given what is known about the decussation (or crossover) of the pathways from visual field to brain, it was assumed that superiority of performance in the left visual field (LVF) would implicate superior right-hemisphere processing, and superior right visual field (RVF) performance would implicate lefthemisphere processing.

\section{RESULTS AND DISCUSSION}

There were no reliable differences in any condition between deaf and hearing signers; in fact, none approached an $\alpha$ level of .25. Since their results are so similar, they are combined and presented in the right panel of Figure 1 and compared with the results for nonsigners.

For handshapes designated as alphabetical, signers demonstrated superior accuracy in the RVF: their scores were $81 \%$ correct, compared to $75 \%$ correct in the LVF $[F(1,15)=7.3, p<.02]$. Nonsigners, however, showed a slight, but nonsignificant, advantage for LVF $(71 \%)$ over RVF $(67 \%)$ stimuli. The groups differed reliably in both performance level in this condition $-79 \%$ overall for signers and $69 \%$ for nonsigners $[\mathrm{F}(1,30)=11.7, \mathrm{p}<.002]$ - and 
direction of visual hemifield results $[F(1,30)=15.4$, $\mathrm{p}<.001]$.

All groups showed LVF superiority for discrimination of nonhandshapes: $72 \%$ for LVF vs. $66 \%$ for RVF stimuli $[F(1,30)=9.6, p<.005]$. This result is consistent with findings for similar tasks involving discrimination of slopes of lines (Umilta, Rizzolatti, Marzi, Zamboni, Franzini, Camanda, \& Berlucchi, 1974). There were no visual field advantages for any group when viewing numerical or illegitimate handshapes, nor were there performance level differences for other than the alphabetical handshapes.

Since no hemifield effect accrued for numerical handshapes, which all viewers could name, the signers' RVF advantage for alphabetical stimuli is not likely to be due to a simple naming strategy. In fact, visual field effects were strikingly similar for those stimuli that all participants could name (numerical) and for those that none could name (illegitimate). Moreover, the signers' results cannot easily be interpreted as simple evidence of left-hemisphere language processing. The reason for this is that an RVF advantage for signers was demonstrated in only one of two conditions involving linguistically relevant handshapes. Although it is possible that a ceiling effect has obscured such a pattern in the numerical condition, we think this unlikely since overall performance here was not particularly high for laterality studies.

The data can be explained, however, in terms of a view that suggests that the left hemisphere specializes in focal or analytic processing and the right hemisphere specializes in diffuse or holistic processing (Bever, 1975; Semmes, 1968). From the analyses of Lane et al. (1976), we determined that the pairs of stimuli in the alphabetical condition differed, on the average, by only 1.3 distinctive features. Pairs of numerical handshapes, on the other hand, differed by a mean of 2.2 features. Perhaps signers, attuned to the featural dimensions defining different handshapes, were forced to adopt a more analytic strategy in detecting the minimal differences between pairs in the former condition. Nonsigners, of course, would not have the knowledge of sign to be able to do so.

A post hoc analysis lends support to this interpretation. Alphabetical pairs were separated according to whether they differed by one or two features. For signers, those pairs differing by a single feature showed a significant asymmetry in favor of the RVF $[t(15)=2.5, p<.025$, two-tailed], whereas those differing by two features did not. On the other hand, nonsigners showed no asymmetry for pairs differing by one feature, but a near-reliable LVF advantage for those differing by two features [t(15) $=1.86, \mathrm{p}<.08]$.

\section{Comparison With Other Studies}

We regard our results as rather straightforward and not unreasonable - at least, no single result conflicts with general notions of cerebral specialization and of sign. The same can be said of the results of several other studies, in particular the two studies that share most in common with ours (Phippard, 1977; Poizner \& Lane, 1979). Yet, the results of all three are by no means the same. Differences occur primarily in the exchange of significant results and nonsignificant results. In particular, Phippard (1977) found no hemisphere differences in signers for handshapes from the manual alphabet, where we have found left-hemisphere effects; and Poizner and Lane (1979) found right-hemisphere differences for numerical and for illegitimate handshapes where we found none for either, and they found no hemisphere effect for geometric shapes where we found significant right-hemispheric effects.

Slight differences in subject populations and in experimental procedures could contribute to these differences. For example, Phippard (1977) mentions that her participants were prelingually deaf, but without specification that they were born deaf of deaf parents, it is unlikely that her sample matches ours and that of Poizner and Lane. The reason for this is that only 1 out of 12 deaf people have deaf parents (Schein \& Delk, 1974). Moreover, children born deaf of hearing parents may not be diagnosed as deaf until relatively late, are more likely to be taught in an oralist manner, and are unlikely to acquire sign like deaf children of deaf parentsthat is, as a native language.

Phippard also offers no mention of counterbalancing of task orders, suggesting that, unlike us, she did not. The sequencing of conditions in laterality studies is known to affect results (Kimura \& Durnford, 1974), and contributes to problems of interpretation, not only in Phippard's (1977) study, but in others of a similar vein (Manning, Goble, Markham, \& LaBreche, 1977; McKeever, Hoemann, Florian, VanDeventer, 1976).

Poizner and Lane's (1979) study differs from ours in dependent measure: they used reaction time, whereas we used percent correct. These are often thought to tap roughly the same, although certainly not identical, psychological resources. Results could differ here with no necessarily theoretical conflict, but we can suggest no mechanism to account for them. Nonetheless, one possibility for explaining the cross-study discrepancy resides in the fact that, in order to make all tasks of roughly equal difficulty, Poizner and Lane (1979) varied exposure durations of their stimuli. This may have some effect on the results, expecially given that their results and exposure times covary.

\section{SUMMARY}

Our results agree with two major points expressed by Poizner and Battison (in press). First, auditory 
experience is unnecessary for lateral specialization per se, and second, cerebral specialization for language is generally similar for deaf, native signers and for nondeaf, native speakers of any oral language. Both conclusions are supported by comparable performance of the deaf and the hearing signers on the alphabetical task. Our results disagree in detail with specific findings of previous studies. However, such differences may be attributable to differences in subject population, known to be an important factor in sign language research, or to differences in methodology.

\section{REFERENCES}

Bever, T. G. Cerebral asymmetries in humans are due to the differentiation of two incompatible processes: Holistic and analytic. In D. Aaronson \& R. Rieber (Eds.), Developmental psycholinguistics and communication disorders. New York Academy of Sciences, 1975, 263, 251-262.

Bever, T. G., \& Chiarello, R. J. Cerebral dominance in musicians and nonmusicians. Science, 1974, 185, 537-539.

Kimura, D., \& Durnford, M. Normal studies in the function of the right hemisphere in vision. In S. J. Dimond \& J. G. Beaumont (Eds.), Hemisphere function in the human brain. New York: Wiley, 1974.

Lane, H., Boyes-Braem, P., \& Bellugi, U. Preliminaries to a distinctive feature analysis of handshapes in American Sign Language. Cognitive Psychology, 1976, 8, 263-289.

Manning, A. A., Goble, W., Markman, R., \& LaBreche, T. M. Lateral cerebral differences in the deaf in response to linguistic and nonlinguistic stimuli. Brain and Language, 1977, 4, 309-321.

McKeever, W. F., Hoemann, H. W., Florian, V. A., \& VANDEVEnTER, A. D. Evidence of minimal cerebral asymmetries for the processing of English words and American Sign
Language in the congenitally deaf. Neuropsychologia, 1976, 14, 338-352.

Patterson, K., \& Bradshaw, J. L. Differential hemispheric mediation of nonverbal visual stimuli. Journal of Experimental Psychology: Human Perception and Performance, 1975, 1, 246-252.

Phippard, D. Hemifield differences in visual perception in deaf and hearing subjects. Neuropsychologia, 1977, 15, 555-561.

Poizner, H., \& Battison, R. Cerebral asymmetry for sign language: Clinical and experimental evidence. In $\mathrm{H}$. Lane \& F. Grosjean (Eds.), Recent perspectives on American Sign Language. Hillsdale, N.J: Erlbaum, in press.

Poizner, H., Battison, R., \& Lane, H. Cerebral asymmetry for perception of American Sign Language: The effects of moving stimuli. Brain and Language, 1979, 7, 351-362.

Poizner, H., \& LANe, H. Cerebral asymmetry in the perception of American Sign Language. Brain and Language, 1979, 7, 210-226.

Schein, J., \& Delk, M. T. Deaf population of the United States. Washington, D.C: National Association for the Deaf, 1974.

Searleman, A. A review of right hemisphere linguistic capabilities. Psychological Bulletin, 1977, 84, 503-528.

Semmes, J. Hemispheric specialization: A possible clue to mechanism. Neuropsychologia, 1968, 6, 11-26.

Umilta, C., Rizzolatti, G., Marzi, C. A., Zamboni, G., Franzini, C., Camanda, R., \& Berlucchi, G. Hemispheric differences in the discrimination of orientation. Neuropsychologia, 1974, 12, 165-174.

\section{NOTE}

1. Many may recognize the upper right illegitimate handshape as the Vulcan sign for "live long and prosper." Few of our participants, however, recognized it as such.

(Received for publication October 1, 1979; accepted October 15, 1979.) 